\title{
Selected faecal bacteria and nutrients essential for antagonism of Salmonella typhimurium in anaerobic continuous flow cultures
}

\author{
T. USHIJIMA and A. SETO \\ Department of Microbiology, Shiga University of Medical Science, Otsu, Shiga 520-21, Japan
}

\begin{abstract}
Summary. As few as five of the species of bacteria commonly found in human faeces-Escherichia coli, Enterobacter aerogenes, Enterococcus faecalis, Bacteroides ovatus and Fusobacterium varium - when grown together in anaerobic continuous flow cultures exerted antagonistic effects on Salmonella typhimurium as great as those given by mixed bacteria from extracts of human faeces. In a single culture, the population of S. typhimurium was c. $10^{8} \mathrm{cfu} / \mathrm{ml}$ but in mixed cultures with the five antagonistic bacteria or mixed faecal bacteria it was reduced to $c .10^{3} \mathrm{cfu} / \mathrm{ml}$. Antagonism appeared to be the result of competition for the growth limiting amino acids, arginine, serine, threonine and aspartic acid. Optimal manifestation of antagonism required the presence of carbon sources fermentable only by antagonistic bacteria, such as lactose $0.1 \%, \mathrm{w} / \mathrm{v}$, sucrose $0.1 \%(\mathrm{w} / \mathrm{v})$ and starch $0 \cdot 2-0.3 \%$ $\mathrm{w} / \mathrm{v}$. These carbohydrates promoted the growth of the antagonistic bacteria, particularly $E$. coli and B. ovatus. However, an increase in concentration by several fold of any one of four growth-limiting amino acids in the medium diminished the antagonistic effects and the population of $S$. typhimurium rose $10^{2}-10^{3}$-fold.
\end{abstract}

\section{Introduction}

Competitive exclusion by the normal bacterial flora is considered to be the main mechanism of elimination of various enteropathogens from the intestinal tract of man and animals. This principle has been applied successfully to eliminate food-poisoning Salmonella spp. from the intestinal tract of animals. ${ }^{1}$ Food poisoning by $S$. typhimurium and $S$. enteritidis has been increasing recently in England ${ }^{2}$ and the USA, ${ }^{3}$ partly through an increase in eggs and chicken meat contaminated by salmonellae. One of the best ways to prevent this has been to administer orally to newly hatched chickens a mixture of pure cultures of bacteria from the caecal flora of adult chickens. ${ }^{4}$ However, the main bacterial species and the precise mechanisms responsible for the competitive exclusion of salmonellae are unknown.

The anaerobic continuous flow (CF) culture method has been considered to be an excellent tool for in-vitro studies of interactions among colonic bacteria. ${ }^{5,6}$ Through its use we found that $S$. typhimurium was the most resistant of several enteropathogens to the antagonistic effects of some bacteria from human faeces. ${ }^{7}$ In this study, identification was made of nutrients and a group of bacterial species of the normal human faecal flora essential for the antagonism of the growth of $S$. typhimurium in anaerobic CF cultures.

Received 16 Oct. 1990; accepted 4 Dec. 1990.

\section{Materials and methods}

\section{Bacterial strains}

Bacteria used were Escherichia coli strain, SU 5034, ATCC 25922, ATCC 11775 and IFO 12713, S. typhimurium strain LT-2, Enterobacter aerogenes strain IFO 13534, Bacteroides ovatus strain SU 39, Fusobacterium varium strain ATCC 8501 and Enterococcus faecalis strain IFO 12969. Most strains were obtained from the American Type Culture Collection (ATCC) and Institute for Fermentation, Osaka (IFO). Others were stock cultures from this laboratory (SU: Shiga University). Some of the biological characteristics of these bacteria are shown in table I.

\section{Inocula}

Bacteria were cultivated in semi-solid (agar $0 \cdot 1 \%$ $\mathrm{w} / \mathrm{v}$ ) maintenance medium ${ }^{8}$ at $37^{\circ} \mathrm{C}$ for $18-20 \mathrm{~h}$ in air. Cultures were suspended in sterile saline at a concentration of c. $5 \times 10^{8} \mathrm{cfu} / \mathrm{ml}$ (McFarland tube No. 3-4). Fresh human faeces was suspended in sterile saline (1:9) and homogenised by a Teflon homogeniser. The preparation was allowed to settle for $10 \mathrm{~min}$ and $0.1 \mathrm{ml}$ of the upper layer was inoculated into tubes $(12 \times$ $120 \mathrm{~mm}$ ) of semi-solid maintenance medium and incubated at $37^{\circ} \mathrm{C}$ for $20 \mathrm{~h}$. Cultures were suspended in sterile saline to the same density as that of the pure 
Table I. Some characteristics of the bacterial strains used

\begin{tabular}{|c|c|c|c|c|c|c|c|}
\hline \multirow{2}{*}{ Organism } & \multicolumn{3}{|c|}{ Fermentation* of } & \multicolumn{4}{|c|}{ Consumption of amino acids in MCM medium } \\
\hline & sucrose & lactose & sorbose & arginine & serine & threonine & aspartic acid \\
\hline E. coli SU 5034 & + & + & + & $+\dagger$ & + & + & + \\
\hline ATCC 25922 & - & + & + & + & + & + & + \\
\hline ATCC 11775 & - & + & + & - & + & + & + \\
\hline IFO 12713 & - & + & - & - & + & + & + \\
\hline S. typhimurium LT-2 & - & - & - & + & + & + & + \\
\hline Ent. aerogenes IFO 13534 & + & + & - & - & + & + & + \\
\hline B. ovatus SU $39 \ddagger$ & + & + & + & - & + & + & + \\
\hline F. varium ATCC $8501 \S$ & - & - & - & - & + & + & + \\
\hline Ec. faecalis IFO $12969^{\circ}$ & + & + & - & + & + & - & - \\
\hline
\end{tabular}

$*+$, Fermentation; - , No fermantation.

+ Residual quantities of most of these amino acids in single anaerobic static cultures containing MCM medium (glucose $0.05 \%$, starch $0.2 \%$ ) were $\leqslant 10 \mu \mathrm{M}$.

$\ddagger$ Starch fermenting strain.

$\S$ Glutamic acid utilising strain.

culture suspensions. A portion (1.5-2 $\mathrm{ml})$ of the cell suspension was used as the inoculum.

\section{Analysis of the interaction of different bacteria in the anaerobic $C F$ culture system}

Analysis of the interaction of different bacteria was made in an anaerobic CF culture system (fig. 1). ${ }^{9}$ The $\mathrm{CF}$ culture was incubated at $37^{\circ} \mathrm{C}$ and stirred by a Teflon covered magnetic stirring bar $(20 \mathrm{~mm}$ long,

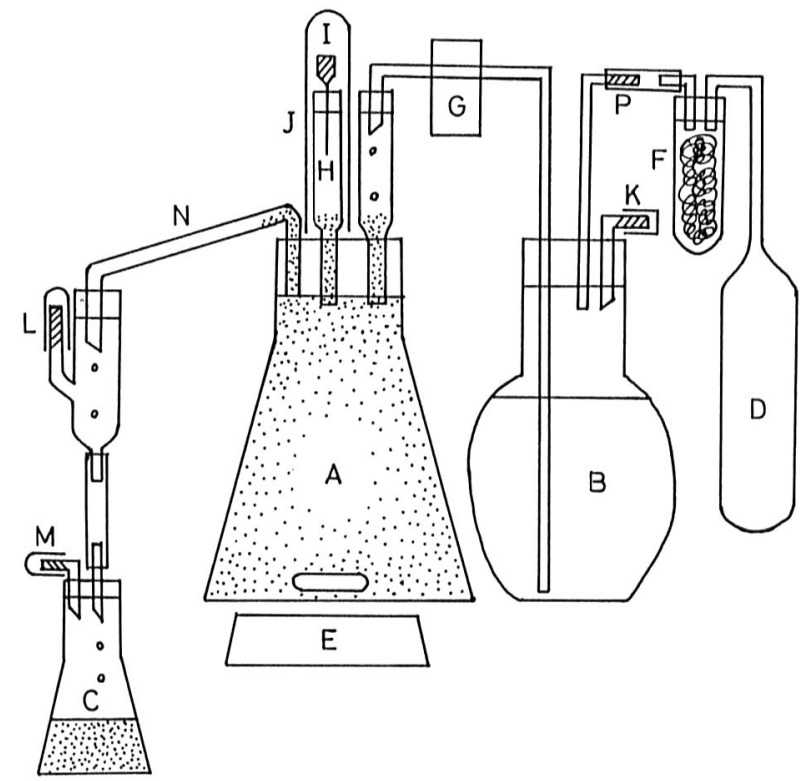

Fig. 1. Schematic figure of the anaerobic continuous flow culture system. ${ }^{9} \mathbf{A}$, growth vessel (Erlenmeyer flask) filled with $c .120 \mathrm{ml}$ of culture medium (excess culture medium is expelled spontaneously through a siphon), $\mathbf{N} ; \mathbf{B}$, fresh medium reservoir; $\mathbf{C}$, collecting flask; $\mathbf{D}$, rubber bladder filled with nitrogen; E, magnetic stirrer; $\mathbf{F}$, oxygen-absorbing bottle filled with steel wool treated with $\mathrm{CuSO}_{4}$ $1 \%$ in distilled water with Tween $800.05 \%, \mathrm{pH} \leqslant 2 ;{ }^{10} \mathrm{G}$, peristaltic pump; $\mathbf{H}$, port for inoculation and sampling of bacteria; I, gas outlet needle with cotton wool plug; $\mathbf{J}$, plastic cap for preventing contamination of the port; $\mathbf{K}$, nitrogen gas inlet tube with cotton plug (the air of the vessel, $\mathbf{B}$, was expelled by flushing with nitrogen gas and then the tip of the tube was capped tightly with a rubber stopper); $\mathbf{L}$ and $\mathbf{M}$, air inlet and outlet tubes with cotton wool plug; $\mathbf{P}$, cotton wool plug to prevent contamination of bottle $\mathbf{B}$.
$6 \mathrm{~mm}$ diam.) at 300-400 rpm to prevent sedimentation and clumping of bacterial cells. The dilution rate of the culture medium was $0 \cdot 05 / \mathrm{h}$. MCM (mock contents of the caecum of mice) medium ${ }^{7,11}$ without acetic, propionic, butyric, lactic and succinic acids was the basal medium for cultivation of bacteria in the CF cultures. In the preliminary study, ${ }^{12}$ a medium optimally suited for demonstrating antagonistic effects on $S$. typhimurium in anaerobic CF cultures had been devised. This was the basal MCM medium supplemented with starch $0.2 \% \mathrm{w} / \mathrm{v}$, glucose $0.05 \% \mathrm{w} / \mathrm{v}$, lactose $0.1 \% \mathrm{w} / \mathrm{v}$, sucrose $0.1 \% \mathrm{w} / \mathrm{v}$ and sorbose $0.05 \% \mathrm{w} / \mathrm{v}$. The number of viable cells of each bacterial species co-cultivated in the CF cultures was determined by counting on selective media.

\section{Selective media}

The selective media for viable counting of bacteria have been reported previously. ${ }^{8,13} \mathrm{E}$. coli was recovered on ALPPL medium without penicillin and lincomycin but supplemented with sorbose $0.05 \% \mathrm{w} / \mathrm{v}$ to stimulate growth of some $E$. coli strains. Ent. aerogenes was counted in ASC medium supplemented with ampicillin $1 \mu \mathrm{g} / \mathrm{ml}$ instead of streptomycin and colimycin.

\section{Analysis of residual amino acids in culture media}

Bacteria were removed from the static or CF culture media by centrifugation at $4000 \mathrm{~g}$ for $15 \mathrm{~min}$ and the clear supernate was filtered through membranes of $0.45-\mu \mathrm{m}$ pore size. One portion of the filtrate was mixed with two portions of sulphosulthilate solution $5 \% \mathrm{w} / \mathrm{v}$ and centrifuged at $4000 \mathrm{~g}$ for $10 \mathrm{~min}$. The clear supernate $(100 \mu \mathrm{l})$ was applied to a JLC-200A automatic amino-acid analyser (Japan Electron Optics, Co. Ltd, Tokyo) equipped with glass column $(6 \times$ $120 \mathrm{~mm}$ ) packed with cation exchange resin, CK-10U (Mitsubishi Kasei Co. Ltd). 


\section{Results}

Comparison of the antagonistic effects of five selected species and mixed human faecal bacteria in CF cultures containing optimum MCM medium

The final population level of $S$. typhimurium growing alone in the CF culture system containing optimum MCM medium was $c .1 .2 \times 10^{8} \mathrm{cfu} / \mathrm{ml}$. However, the final population of S. typhimurium in CF cultures cocultivated with either the selected five faecal bacterial species, including arginine-consuming $E$. coli strain SU 5034, or mixed faecal bacteria was $c .10^{3} \mathrm{cfu} / \mathrm{ml}$ (fig. 2). These results indicate clearly that the mixture of the five faecal species showed antagonistic effects as potent as those produced by mixed faecal bacteria. The omission of any one of the five bacterial species resulted in a decrease in antagonistic effect (table II). Thus manifestation of optimum antagonistic effects required the presence of all five bacterial species, but not of other bacteria.

\section{Influence of sugars in the media on the antagonistic effect}

When the five antagonistic bacterial species and $S$. typhimurium were co-cultivated in the $\mathrm{CF}$ culture system containing optimum MCM medium without
Table II. Influence of omission of one of the five antagonistic bacterial species on the population level of $S$. typhimurium in anaerobic $\mathrm{CF}$ cultures

\begin{tabular}{|c|c|c|c|c|c|c|}
\hline \multirow{2}{*}{ Strain } & \multicolumn{6}{|c|}{ Final population $\left(\log _{10} \mathrm{cfu} / \mathrm{ml}\right)^{*}$ in culture no } \\
\hline & 1 & 2 & 3 & 4 & 5 & 6 \\
\hline S. typhimurium & $3 \cdot 06$ & $4 \cdot 96$ & $4 \cdot 13$ & $5 \cdot 26$ & $5 \cdot 98$ & $5 \cdot 73$ \\
\hline E. coli $\mathrm{SU} 5034$ & $8 \cdot 43$ & $-\dagger$ & $8 \cdot 71$ & $8 \cdot 27$ & $7 \cdot 98$ & $8 \cdot 68$ \\
\hline Ent. aerogenes & $7 \cdot 76$ & $8 \cdot 3$ & - & $6 \cdot 86$ & $7 \cdot 94$ & $6 \cdot 32$ \\
\hline Ec. faecalis & $7 \cdot 16$ & $7 \cdot 72$ & $7 \cdot 54$ & - & $7 \cdot 30$ & $6 \cdot 8$ \\
\hline B. ovatus & $9 \cdot 46$ & $9 \cdot 26$ & $9 \cdot 61$ & $9 \cdot 38$ & - & $9 \cdot 41$ \\
\hline F. varium & $3 \cdot 83$ & $6 \cdot 26$ & $5 \cdot 89$ & $5 \cdot 13$ & $6 \cdot 74$ & - \\
\hline $\mathrm{pH}$ of cultures & $6 \cdot 26$ & $6 \cdot 23$ & $6 \cdot 24$ & $6 \cdot 31$ & $6 \cdot 61$ & $6 \cdot 30$ \\
\hline
\end{tabular}

* Mean of population at 2 and 3 days.

$\uparrow$ Strain omitted.

any of the five carbohydrates, the antagonistic effects disappeared almost completely and all bacteria cocultivated persisted in a narrow population range of c. $3 \times 10^{6}-2 \times 10^{7} \mathrm{cfu} / \mathrm{ml}$ (fig. 3 ).

Sucrose and lactose were fermented by the antagonistic bacteria but not by $S$. typhimurium. The population of S. typhimurium co-cultivated with the five antagonistic bacterial species in CF cultures containing optimum MCM medium without lactose and sucrose was $c .10^{6} \mathrm{cfu} / \mathrm{ml}$ (fig. 4A). The population of

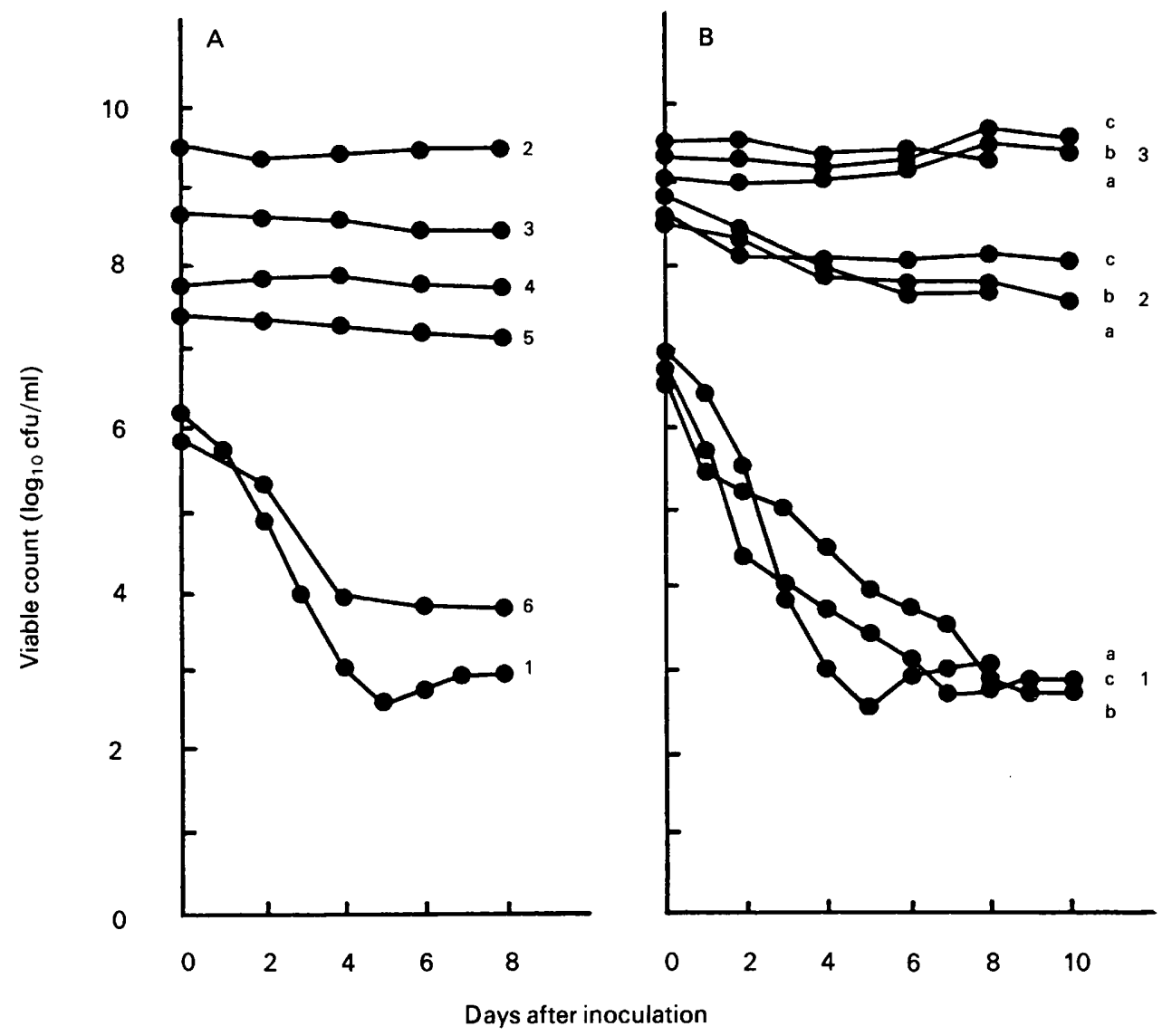

Fig. 2. Comparison of antagonistic effects of five species of faecal bacteria and mixed faecal bacteria on $S$. typhimurium in anaerobic CF cultures containing optimum MCM medium. A, viable counts of $S$. typhimurium (1), B. ovatus (2), E. coli SU 5034 (3), Ent. aerogenes (4), Ec. faecalis (5) and $F$. varium (6) when all were grown together. B, viable counts of $S$. typhimurium (1) and all aerobic (2) and anaerobic (3) bacteria of three samples $(\mathbf{a}, \mathbf{b}, \mathbf{c}$,$) of human faeces when cultured together.$ 


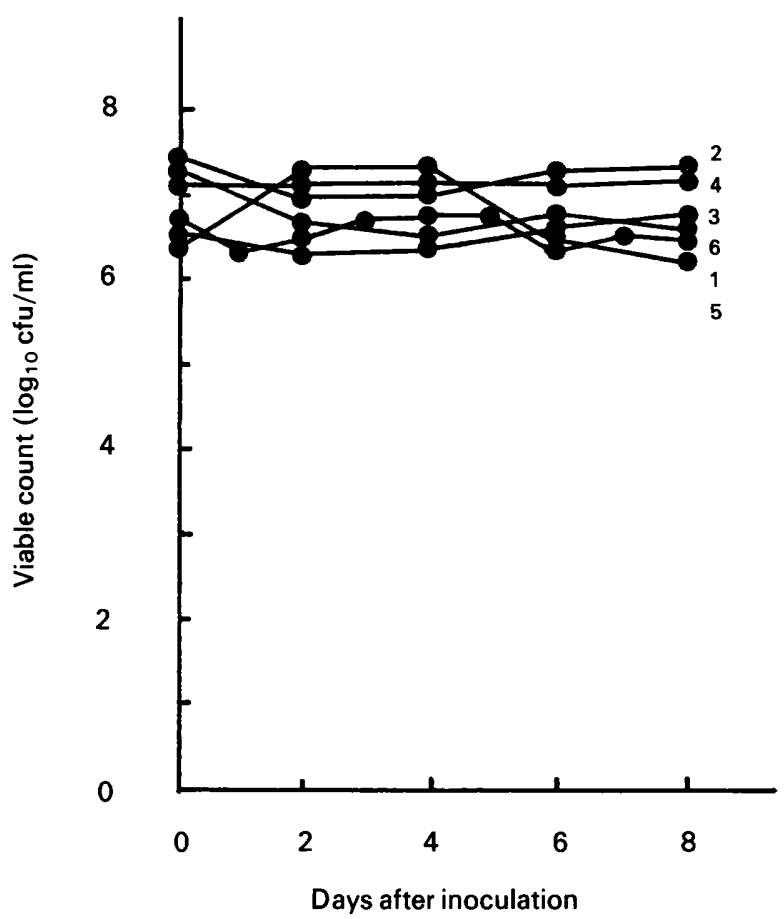

Fig. 3. The viable counts of $S$. typhimurium (1), B. ovatus (2), E. coli $(3)$, Ent. aerogenes (4), Ec. faecalis $(5)$ and $F$. varium (6) when grown together in optimum MCM medium without carbohydrates in the CF culture system.

S. typhimurium gradually decreased as the concentration of these sugars was increased and it reached the lowest level of $c .10^{3} \mathrm{cfu} / \mathrm{ml}$ in the presence of lactose and sucrose $0 \cdot 1 \%$.

Starch was fermented only by B. ovatus. The population of $S$.typhimurium in the $\mathrm{CF}$ culture containing optimum MCM medium devoid of starch was $c .10^{5} \mathrm{cfu} / \mathrm{ml}$. The population of $S$. typhimurium gradually decreased with an increase in starch concentration and reached the lowest level of $c .10^{3} \mathrm{cfu} / \mathrm{ml}$ in the presence of $0.2-0.3 \%$ of starch (fig. 4B).

\section{Comparision of antagonistic effects of arginine- positive and-negative $E$. coli}

In the mixed CF cultures containing the optimum MCM medium and the five faecal bacterial species, the population of $S$. typhimurium was $\geqslant 10^{2}$-fold lower in the presence of arginine-positive $E$. coli than in the presence of arginine-negative $E$. coli (fig. 5A).

In the mixed $C F$ cultures with the five faecal bacterial species including arginine-negative $E$. coli, the population of $S$.typhimurium was $10^{1}-10^{2}$-fold lower in the optimum MCM medium devoid of free arginine than in the optimum medium containing $1400 \mu \mathrm{M}$ of free arginine (fig. 5B).

\section{Influence of increasing concentrations of growth limiting amino acids on the antagonistic effect}

When the concentrations in the optimum MCM medium of any one of the four growth limiting amino acids - arginine, serine, threonine and aspartic acidwas increased by $2000 \mu \mathrm{M}$, the antagonistic effect of the five faecal bacterial species including argininepositive $E$. coli on $S$. typhimurium decreased and the population of $S$. typhimurium increased $10^{2}-10^{3}$-fold (fig. 6A).

The final population of $S$. typhimurium in both of
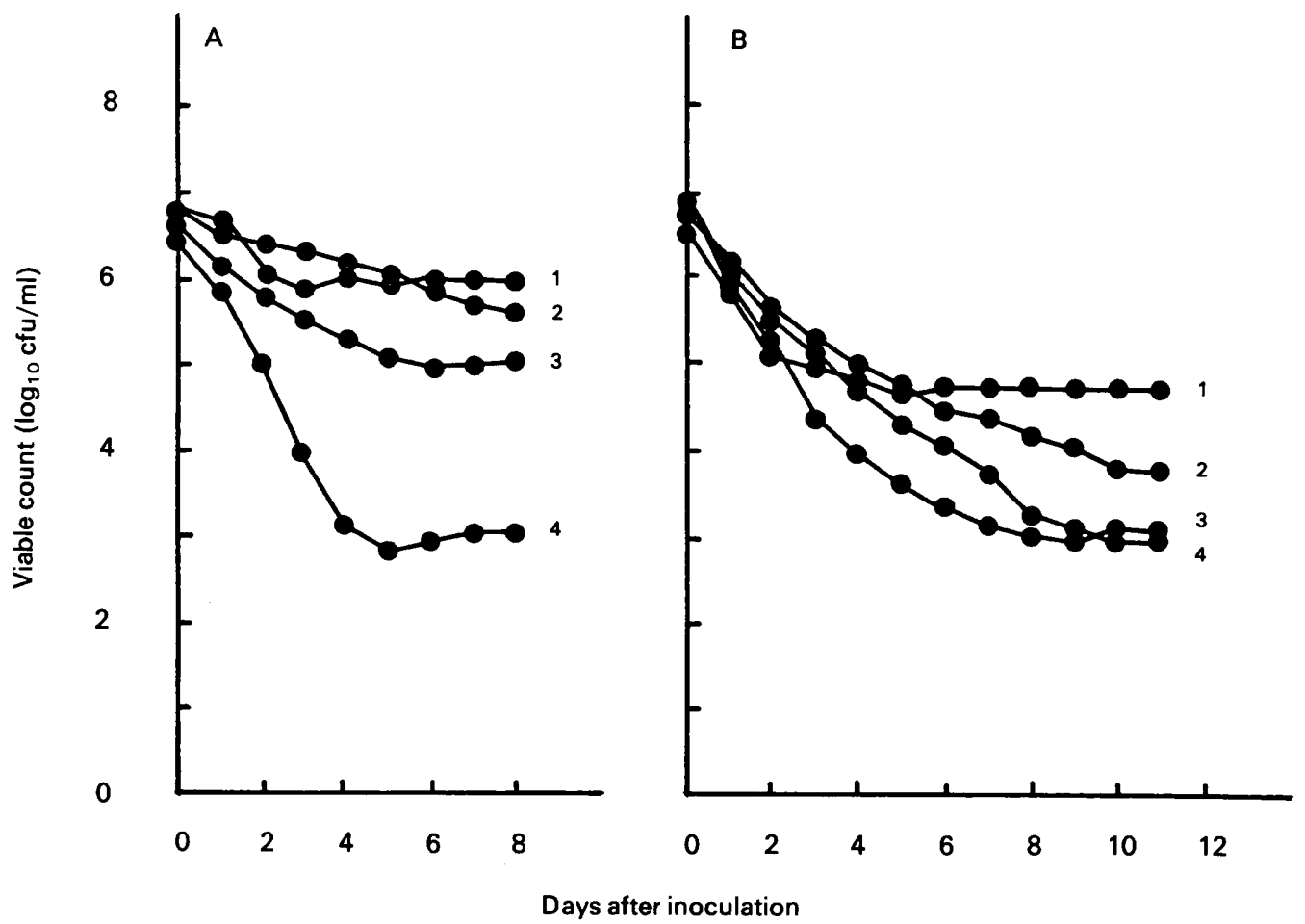

Fig. 4. Influence of carbohydrate concentration in the optimum MCM medium on the population level of $S$. typhimurium in mixed anaerobic $\mathrm{CF}$ cultures with the five faecal bacterial species. A, lactose and sucrose: $1,0 \% ; 2,0 \cdot 01 \% ; 3,0 \cdot 05 \% ; 4,0 \cdot 1 \%$. B, starch: $1,0 \% ; 2,0 \cdot 1 \% ; 3$, $0 \cdot 2 \% ; 4,0 \cdot 3 \%$. 


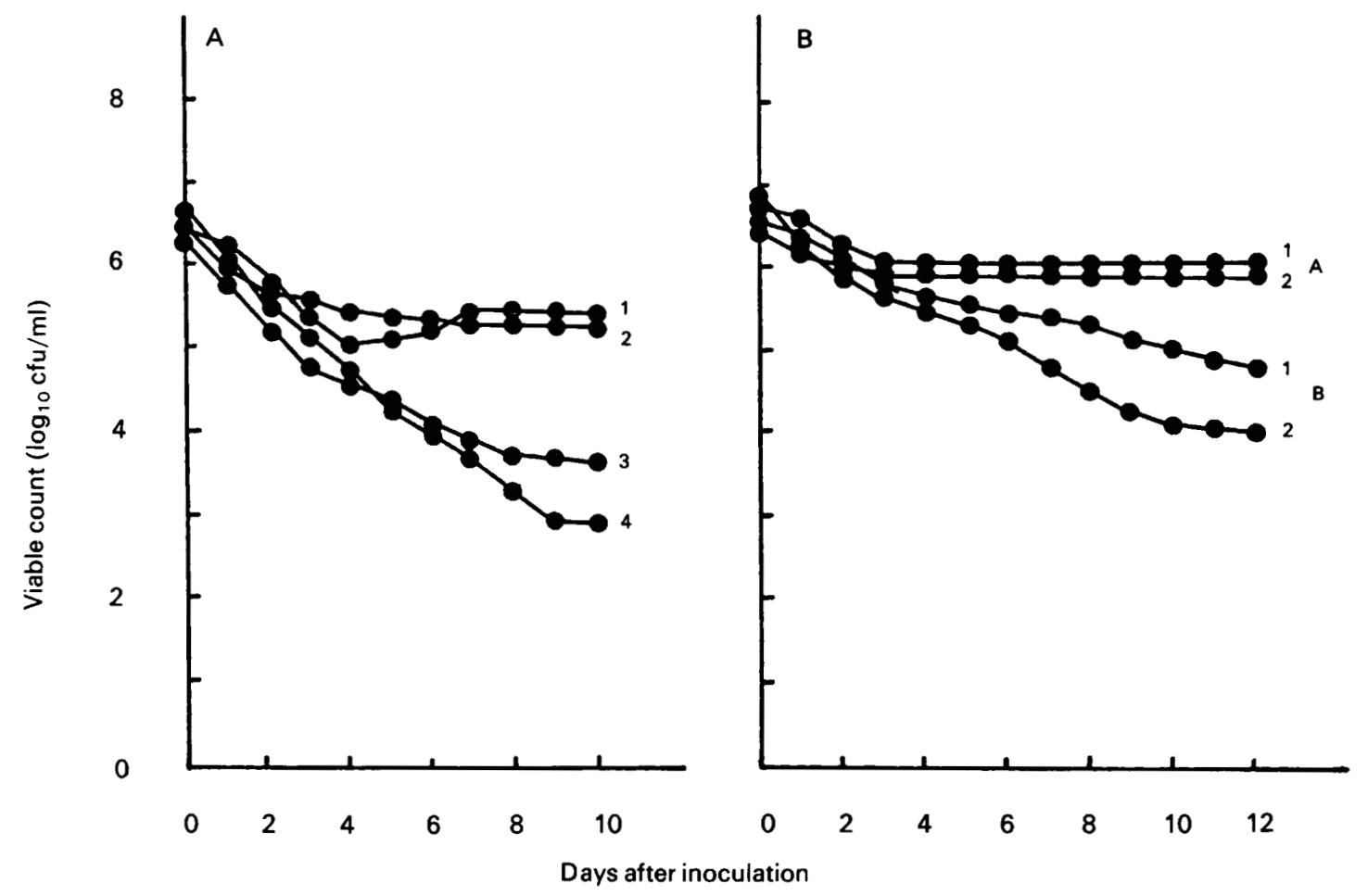

Fig. 5. Comparison of the antagonistic effects of the five faecal bacterial species on S. typhimurium in optimum MCM medium when: A. the E. coli representative strain was arginine negative, IFO 12713 (1), ATCC 11775 (2) and arginine positive ATCC 259221 (3), SU 5034 (4); B, the E. coli strains included both arginine negative strains IFO 12713 (1) and ATCC 11775 (2), in the optimum MCM medium with (A) and without (B) $1400 \mu \mathrm{M}$ arginine.
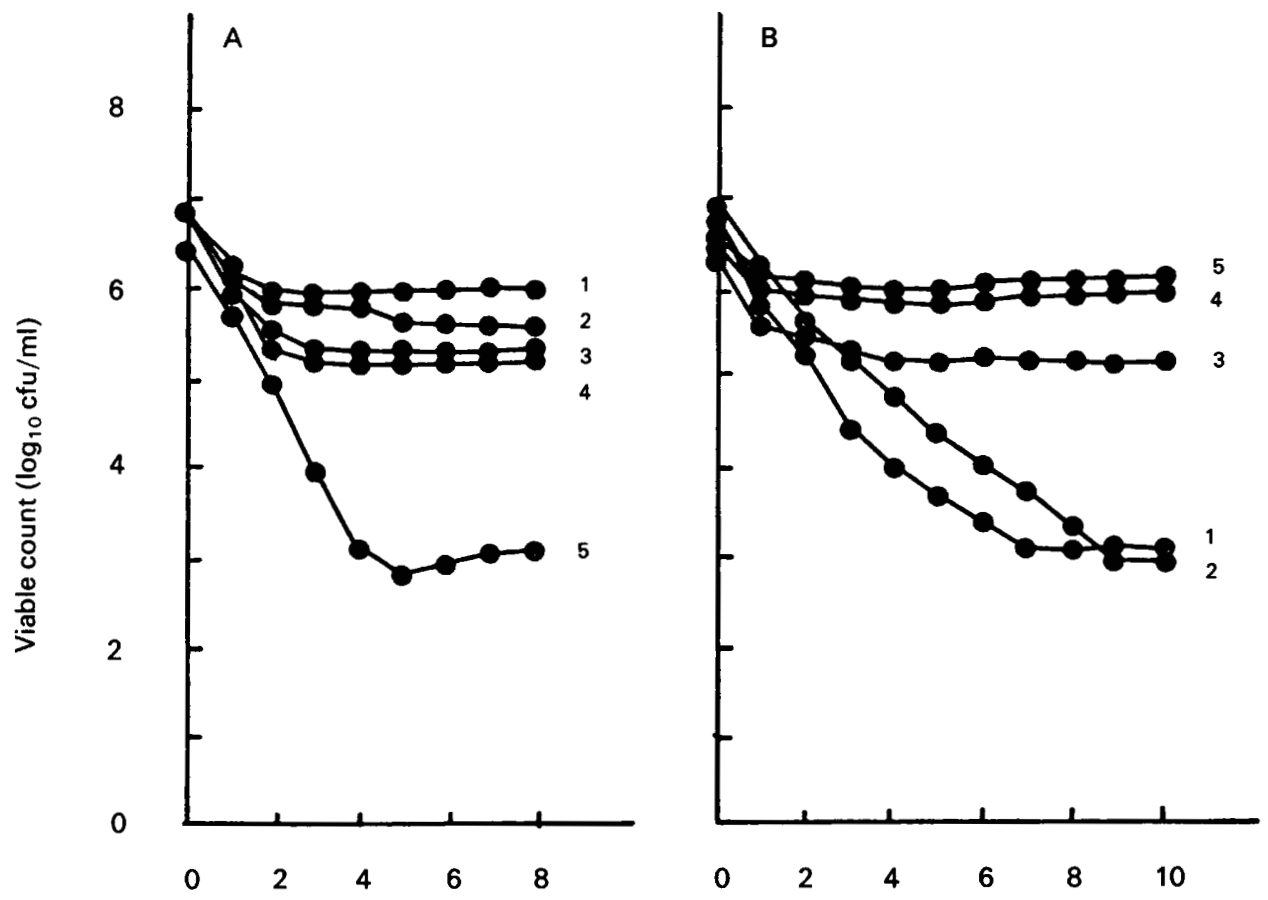

Days after inoculation

Fig. 6. Influence of four growth-limiting amino acids on the populations of $S$. typhimurium in mixed CF cultures with the five faecal bacterial strains shown in fig. 2A. A, addition of $2000 \mu \mathrm{M}$ of arginine (1), serine (2), threonine (3) and aspartic acid (4), to the optimum MCM medium (5); B, addition of various amounts of arginine $-95 \mu \mathrm{M}$ (2), $345 \mu \mathrm{M}$ (3), $595 \mu \mathrm{M}$ (4), $2095 \mu \mathrm{M}$ (5) - to the optimum MCM medium without free arginine (1). 
the CF cultures containing MCM medium with and without $95 \mu \mathrm{M}$ free arginine was the same. Additional increases of arginine resulted in a gradual elevation of the $S$. typhimurium population to a maximum in the presence of $595 \mu \mathrm{M}$ arginine (fig. 6B).

\section{Residual amino acids in the $C F$ culture media}

In the mixed CF cultures containing MCM medium supplemented with either 95 or $595 \mu \mathrm{M}$ arginine, concentrations of most of the four growth-limiting amino acids were $\leqslant 5 \mu \mathrm{M}$ (table III).

Table III. Residual concentration of the four growth-limiting amino acids after growth in mixed anaerobic CF cultures of five antagonistic faecal bacterial species and $S$. typhimurium

\begin{tabular}{|c|c|c|c|}
\hline \multirow{3}{*}{ Amino acid } & \multicolumn{3}{|c|}{$\begin{array}{l}\text { Concentration of growth-limiting amino acid } \\
\qquad(\mu \mathrm{M}) \text { in }\end{array}$} \\
\hline & \multicolumn{2}{|c|}{$\begin{array}{l}\text { CF medium with } \\
\text { arginine }(\mu \mathrm{M})\end{array}$} & \multirow{2}{*}{$\begin{array}{c}\text { uninoculated } \\
\text { medium } \\
\text { with } 95 \mu \mathrm{M} \text { arginine }\end{array}$} \\
\hline & 95 & 595 & \\
\hline Arginine & $1 \cdot 1$ & 1.7 & 89 \\
\hline Serine & $<1 \cdot 0$ & $2 \cdot 7$ & 136 \\
\hline Threonine & $5 \cdot 3$ & $2 \cdot 6$ & 300 \\
\hline Aspartic acid & $4 \cdot 6$ & $14 \cdot 6$ & 76 \\
\hline
\end{tabular}

\section{Discussion}

With only five of the bacterial species commonly found in human faeces-E. coli, Ent. aerogenes, Ec. faecalis, B. ovatus and $F$. varium, antagonistic effects against $S$. typhimurium could be produced in anaerobic CF cultures as potent as those given by mixed bacteria from extracts of human faeces. It appeared that this was achieved by competition for growth-limiting nutrients, such as arginine, serine, threonine and aspartic acid.

Hudault et al. ${ }^{14}$ showed potent antagonistic effects of caecal flora of conventional chickens on $S$. typhimurium in gnotobiotic mice and chickens. Regrettably however, they did not find any combinations of bacterial species that showed antagonistic effects on S. typhimurium as potent as those of whole caecal flora.

In attempting to develop a pure-culture treatment, many authors reported that chickens were successfully protected against colonisation by $S$. typhimurium when given a pure culture of, e.g. Ec. faecalis, ${ }^{15}$ or Clostridium spp., ${ }^{16}$ or E. coli, ${ }^{17}$ or various Salmonella spp. ${ }^{18}$ However, Impey et al..$^{4}$ suggested that not only was a limited number of strains unlikely to confer complete protection but that they may disturb the ecological balance of the intestinal tract. They found a group of bacterial strains which, when administered orally, prevented colonisation by $S$. typhimurium of the caeca of newly hatched chickens. The treatment conferred the same protection as that given by a suspension of the caecal contents of adult chickens. The group comprised as many as 48 different bacteria including several unidentified isolates.

Most previous studies, including the latter on the antagonistic effects of intestinal bacteria on $S$. typhimurium, have been made in conventional animals and thus it is difficult to distinguish between the role of the inoculated bacteria and that of bacteria already present in the intestinal tract. The mechanisms by which colonic bacteria normally antagonise S. typhimurium and other food poisoning Salmonella spp. are difficult to study in vivo even if gnotobiotes are employed, because precise manipulation of the growth environment is not possible. Anaerobic CF cultures can reproduce many of the bacterial interactions that occur in the large intestine and the mechanisms which regulate in vivo the bacterial population. ${ }^{5,6}$ Moreover, the various factors that influence these interactions are more easily controlled.

In mixed anaerobic $\mathrm{CF}$ cultures, potent antagonistic effects on $S$. typhimurium were manifest only in the presence of all five bacterial species, including an $E$. coli strain that had the ability to utilise arginine, serine, threonine and aspartic acid. S. typhimurium also actively utilised these amino acids. Substitution of the arginine-utilising E. coli strain by an argininenegative $E$. coli strain provoked a massive decrease in antagonistic effect. In this situation, the amount of arginine available to $S$. typhimurium may be increased and, thus, this bacterium may be able to reach a higher population density. This assumption was supported by the fact that, in optimal MCM medium without free arginine, both clusters of the five antagonistic bacteria including either an arginine-positive or an arginine-negative $E$. coli strain showed similar potent antagonistic effects.

In addition, the presence of some carbohydrates, such as sucrose, lactose and starch, which were fermented only by antagonistic bacteria, was also necessary for manifestation of the potent antagonistic effects. Inclusion of these carbohydrates in the MCM medium promoted a large increase in the population of the antagonistic bacteria, especially E. coli and $B$. ovatus, and thereby a diminution in the amount of growth-limiting nutrients.

Even in the optimal conditions for manifestation of the antagonistic effects, i.e., in the presence of arginine-consuming E. coli and carbohydrates fermentable by only the antagonistic bacteria, an increase of several-fold of only one of the growth-limiting nitrogen sources-arginine, serine, threonine or aspartic acid-in the optimal MCM medium resulted in a sharp decrease in the antagonistic effects, and the population of S. typhimurium increased $10^{2}-10^{3}$-fold.

An increase in the free arginine concentration of the optimum MCM medium from 0 to $95 \mu \mathrm{M}$ did not influence the population of S.typhimurium in the mixed CF cultures. However, further increases in the arginine concentration promoted growth of 
$S$. typhimurium to the maximum level at an arginine concentration of $595 \mu \mathrm{M}$. The residual amount of most of the four growth-limiting amino acids in the CF cultures in optimum MCM media supplemented with either $95 \mu \mathrm{M}$ or $595 \mu \mathrm{M}$ arginine was $\leqslant 5 \mu \mathrm{M}$. In these culture environments of low concentrations of growthlimiting amino acids, the five antagonistic bacterial species and $S$. typhimurium competed with one another, particularly for arginine, and this resulted in c. $10^{3}$-fold difference in the population of S. typhimurium.

These results indicate clearly that the mechanism of antagonism of the five bacterial species on $S$. typhimurium was the competition for growth-limit-

\section{References}

1. Snoeyenbos GH, Weinack OM, Soerjadi-Liem AS, Miller BM, Woodward DE, Weston CR. Large-scale trials to study competitive exclusion of Salmonella in chickens. Avian Dis 1985; 29 : 1004-1011.

2. Humphrey TJ, Mead GC, Rowe B. Poultry meat as a source of human salmonellosis in England and Wales. Epidemiol Infect 1988; 100: 175-184.

3. Anon. Increasing rate of Salmonella enteritidis infections associated with consumption of raw and undercooked eggs. N Y State J Med 1988; 88: 90-91.

4. Impey CS, Mead GC, George SM. Competitive exclusion of salmonellas from the chick caecum using a defined mixture of bacterial isolates from the caecal microflora of an adult bird. J Hyg 1982; 89: 479-490.

5. Freter R, Stauffer E, Cleven D, Holdeman LV, Moore WEC. Continuous-flow cultures as in-vitro models of the ecology of large intestinal flora. Infect Immun 1983; 39: 666-675.

6. Freter $\mathbf{R}$, Brickner $H$, Botney $M$, Cleven D, Aranki A Mechanisms that control bacterial populations in continuous-flow culture models of mouse large intestinal flora. Infect Immun 1983; 39: 676-685.

7. Ushijima T, Ozaki Y. Potent antagonism of Escherichia coli, Bacteroides ovatus, Fusobacterium varium, and Enterococcus faecalis, alone or in combination, for enteropathogens in anaerobic continuous flow cultures. $J$ Med Microbiol 1986 ; 22: 157-163.

8. Ushijima T, Takahashi M, Tatewaki K, Ozaki Y. A selective medium for isolation and presumptive identification of the Bacteroides fragilis group. Microbiol Immunol 1983; 27: 985-993.

9. Ushijima T. A simple anaerobic continuous culture system for the study of bacterial symbiosis and antagonism. Med Biol $1984 ; 108: 71-74$.

10. Parker CA. Anaerobiosis with iron wool. Aust J Exp Biol Med Sci $1955 ; 33$ : 33-37. ing amino acids. They verify the hypothesis of Freter et $a .^{6}$ that populations of the colonic flora are controlled by one or a few growth-limiting nutrients.

Omission of any one of the five bacterial species from the mixed CF cultures resulted in a massive decrease of the antagonistic effects. Thus each one contributed to the inhibition of growth of $S$. typhimurium by a mechanism not yet determined.

As suggested by Freter et al., ${ }^{5,6}$ the anaerobic CF culture method can reproduce many of the bacterial interactions that occur in the colon, and these results may contribute to the development of methods for the reduction of food poisoning outbreaks.

11. Ushijima T. Semisynthetic media for in vitro examination of the contribution of nutrients and growth inhibitors for symbiosis and antagonism of the bacteria in ileum, caecum and colon of the mammalian. Med Biol 1983; 106: 199204.

12. Ushijima T. Selected human colonic flora and nutrients inducing potent growth inhibition for Salmonella typhimurium in anaerobic continuous flow cultures. Med Biol 1990; 120: 75-79.

13. Ushijima T, Takahashi M, Ozaki Y. Fourteen selective media facilitate evaluation of populations of coexisting fixed bacterial strains of enteric pathogens and normal human fecal flora. J Microbiol Methods $1985 ; 4: 189-194$.

14. Hudault S, Bewa $\mathbf{H}$, Bridonneau C, Raibaud P. Efficiency of various bacterial suspensions derived from cecal floras of conventional chickens in reducing the population level of Salmonella typhimurium in gnotobiotic mice and chicken intestines. Can J Microbiol 1985; 31: 832-838.

15. Soerjadi AS, Lloyd AB, Cumming RB. Streptococcus faecalis, a bacterial isolate which protects young chickens from enteric invasion by salmonellae. Aust Vet $J 1978 ; 54$ : 549 550.

16. Rigby C, Pettit J, Robertson A. The effect of normal intestinal flora on the Salmonella carrier state in poultry with special reference to $S$. thompson and $S$. typhimurium. In: Barnum DA (ed) Proceedings of the international symposium on Salmonella and prospects for control. Ontario, University of Guelph. 1977; 263.

17. Barrow PA, Tucker JF. Inhibition of colonization of the chicken caecum with Salmonella typhimurium by pre-treatment with strains of Escherichia coli. J Hyg 1986; 96: 161-169.

18. Barrow PA, Tucker JF, Simpson JM. Inhibition of colonization of the chicken alimentary tract with Salmonella typhimurium gram-negative facultatively anaerobic bacteria. Epidemiol Infect 1987; 98: 311-322. 